\title{
BUSINESS PERFORMANCE
}

\section{ASSESSMENTS OF ECONOMIC POLICY IN 2019}

\section{S. Aukutsionek}

DOI: 10.20542/0202-179X-2020-1-3-13

\section{IMEMO}

Abstract: The article describes how the managers of Russia's industrial and agricultural enterprises (the Russian Economic Barometer's respondents) assess the governmental economic policy through the end of 2019. The author presents the data on the proportion of managers who understand and approve this policy and on the high priority measures that they consider necessary to stimulate production.

Keywords: Russia; industry; economic policy; assessment of economic policy of the Government; index of approval; index of comprehension; production incentives; residual duration of the crisis.

The results of managerial opinions' surveys conducted by the Russian Economic Barometer (REB) testify that in 2019, the assessments of government economic policy in the industrial and agricultural sectors remained at approximately the same level as a year before.

\section{Industrial Enterprises}

The share of the REB's respondents who COMPREHEND the Government's economic policy (entirely or mainly) was $28 \%$. This is 5 percentage points less than in 2018.

The share of NON-COMPREHENDING the government actions in 2019 (entirely or mainly) amounted to $23 \%$, which is 3 points less than the 2018 assessment.

For most of the post-default period, the largest group of respondents consisted of those who were undecided in assessing the government

Sergey Aukutsionek, PhD, Director of the Center for Research in Transitional Economy, IMEMO. 
policy. In 2016, however, its share dropped to $34 \%$ and this group lost first place to the group of "understanders". The very same situation was observed in 2017, whereas in 2018 the number of respondents without any opinion increased significantly and this group came out on top again (41\%).This trend became even stronger in 2019 when 49\% of respondents found it difficult to make an assessment.

When answering the question about economic policy, enterprise managers are offered to choose one of five positions: "full incomprehension", "essential incomprehension", "it's hard to say", "essential comprehension", and "full comprehension". Using this fivestage scale, we compile an elaborated Index of Comprehension (IC), which takes into account all grades of answers with relevant weights: 0 ; $1 / 4 ; 1 / 2 ; 3 / 4$ and 1 . The case when $I C=100$ means unified and full comprehension; whereas $\mathrm{IC}=0$, on the contrary, means unified and full incomprehension of the Government's policy.

In terms of such measurement, the Government's actions in 2019 looked rather "understandable" to almost half of enterprise managers. The index of comprehension amounted to $49 \%$ remaining at the same level as in 2018. By historical standards, this is quite a high result. Comprehension of government's policy was even greater only in 20062008 and in $2017-52-53 \%$ (see table 1).

The share of industrial managers who APPROVE OF the governmental economic policy (entirely or mainly) decreased by 5 percentage points over a year and amounted to $14 \%$. While the share of DISAPPROVING ones increased by 4 percentage points - from $26 \%$ to $30 \%$.

As well as for the previous indicator, the measurement is made on a five-stage scale: from complete disapproval to complete approval. The Index of Approval (IA) of the Government's economic policy is constructed in the same mode as the Index of Comprehension. In 2019, its average value was 45 which almost repeated the results of 20142018 and was only two points lower than the record high value of 2007. 
Table 1

Assessments of the Government's Economic Policy (conducted in the last three to four months) and of the Residual Duration of Crisis by Industrial Managers (average data of four quarterly surveys)

\begin{tabular}{|c|c|c|c|c|}
\hline & $\begin{array}{c}\text { Index of comprehension } \\
\text { of Government's } \\
\text { economic policy') }\end{array}$ & $\begin{array}{l}\text { Index of approval of } \\
\text { Government's } \\
\text { economic policy1) }\end{array}$ & $\begin{array}{c}\text { Residual } \\
\text { duration of } \\
\text { crisis, years }{ }^{2)}\end{array}$ & $\begin{array}{l}\text { Share of respondents believing } \\
\text { that economic recovery has } \\
\text { already started, }(\%)\end{array}$ \\
\hline 19923) & 47 & 41 & 6.0 & - \\
\hline 1993 & 40 & 36 & 6.0 & - \\
\hline 1994 & 34 & 26 & 6.3 & - \\
\hline 1995 & 35 & 28 & 7.1 & - \\
\hline 1996 & 32 & 25 & 6.7 & - \\
\hline 1997 & 35 & 25 & 7.8 & - \\
\hline 1998 & 34 & 25 & 7.4 & - \\
\hline 1999 & 39 & 34 & 7.7 & 3 \\
\hline 2000 & 46 & 43 & 6.0 & 9 \\
\hline 2001 & 50 & 46 & 6.4 & 10 \\
\hline 2002 & 51 & 45 & 7.1 & 6 \\
\hline 2003 & 50 & 41 & 7.5 & 6 \\
\hline 2004 & 49 & 41 & 7.6 & 10 \\
\hline 2005 & 49 & 39 & 7.8 & 7 \\
\hline 2006 & 52 & 44 & 7.1 & 12 \\
\hline 2007 & 53 & 47 & 6.8 & 16 \\
\hline 2008 & 52 & 45 & 5.9 & 13 \\
\hline 2009 & 45 & 40 & 4.2 & 2 \\
\hline 2010 & 50 & 44 & 4.4 & 6 \\
\hline 2011 & 47 & 40 & 4.9 & 12 \\
\hline 2012 & 48 & 41 & 5.7 & 10 \\
\hline 2013 & 48 & 42 & 5.7 & 4 \\
\hline 2014 & 49 & 45 & 5.9 & 3 \\
\hline 2015 & 50 & 46 & 5.0 & 0 \\
\hline 2016 & 50 & 46 & 6.0 & 2 \\
\hline 2017 & 53 & 46 & 6.5 & 5 \\
\hline 2018 & 49 & 46 & 7.3 & 6 \\
\hline 2019 & 49 & 45 & 6.9 & 4 \\
\hline
\end{tabular}

1) A 100-point scale: "100" corresponds to the case when all managers comprehend/approve of the policy, while "0" to the case when none of them comprehend/approve of it.

2) In the cases when the respondents believed that the crisis was already over, assessment of residual duration of the crisis was taken as zero.

3) Without the first quarter.

Source: REB surveys. 
As an indirect estimate of the government's activity, one more REB indicator can be used: the expected number of years before the end of the economic crisis. On average for 2019, the RESIDUAL DURATION OF THE CRISIS, according to the REB respondents, was 6.9 years. This is 0.5 years better than the result calculated for 2018 but very far from the optimistic evaluations of 2009-2010, when the end of the crisis was expected already in slightly more than 4 years. The share of top managers defining the current situation as an economic recovery has narrowed a little from $6 \%$ to $4 \%$ of the sample.

Table 2

Assessments of the Government's Economic Policy (conducted in the last three to four months) by Industrial Managers, different branches (average data of four quarterly surveys)

\begin{tabular}{l|c|c|c||c|c|c||c}
\hline \multirow{2}{*}{} & \multicolumn{2}{|c||}{$\begin{array}{c}\text { Index of comprehension } \\
\text { of Government's } \\
\text { economic policy }\end{array}$} & \multicolumn{2}{|c||}{$\begin{array}{c}\text { Index of approval of } \\
\text { Government's } \\
\text { economic policy }\end{array}$} & $\begin{array}{c}\text { Disparity between levels } \\
\text { of comprehension and } \\
\text { approval }\end{array}$ \\
\cline { 2 - 7 } & 2017 & 2018 & 2019 & 2017 & 2018 & 2019 & 2019 \\
\cline { 2 - 7 } & $(1)$ & $(2)$ & $(3)$ & $(4)$ & $(5)$ & $(6)$ & $(7)=(3)-(6)$ \\
\hline $\begin{array}{l}\text { Iron and steel and non- } \\
\text { ferrous metals }\end{array}$ & 46 & 50 & 56 & 50 & 48 & 45 & 11 \\
$\begin{array}{l}\text { Machinery and } \\
\text { metalworking }\end{array}$ & 60 & 54 & 52 & 53 & 52 & 48 & 4 \\
$\begin{array}{l}\text { Chemicals and } \\
\text { petrochemicals }\end{array}$ & 44 & 37 & 45 & 42 & 33 & 41 & 4 \\
Logging, woodworking, \\
pulp-and-paper
\end{tabular}

Source: REB surveys.

Assessments of the Government's economic policy differ significantly by industry (see table 2). A noticeable and favorable (for the Government) shift in comprehension was registered in the iron, steel 
and non-ferrous metals industry: +6 percentage points in comparison with 2018, chemicals and petrochemicals ( +8 points) and building materials $($ also +8$)$ industries. Whereas in the timber industrial complex and food industry a significant subsidence of the index of comprehension was noted: by 10 and 8 percentage points, respectively.

Positive dynamics in assessment of economic policy's approval was observed, first of all, in the timber industrial complex ( +13 points) and in building materials industry (+12 points). The latter industry was the only one where the absolute approval rate exceeded half $(52 \%)$. The government's policy received a noticeable increase in approval in the chemical industry ( +8 points). At the same time, the indicator fell for all other industries. The largest decrease was in the light and food industries ( -6 and -7 points, respectively).

Let us turn now to the list of incentive measures, which, according to the respondents, should be taken by the Government first of all. The alleviation of tax burden continues to be the proposed measure number one. Since 1998-2000, there was a tendency to decrease the acuteness of tax problem. Even in the crisis year of 2009, the frequency of claims to cut down the taxes kept around a record low of $56 \%$ and dropped by another 2 points in 2010. In 2011 it seemed that everything was back to square one: $74 \%$ of respondents considered the reduction of tax burden to be of paramount importance problem of economic policy. This level was on par with the results of 2001-2003. However in 2012, the tendency to reduce the severity of tax problems prevailed once again and in 2014 the relevant rating dropped to $52 \%$, in 2015 and 2016 - to $44 \%$. In 2017-2018, it rose again to 55-53\%. But in 2019, it fell to a record low level of $42 \%$ (see table 3 ). It must be emphasized that the decline of this index is not equivalent to the alleviation of taxes for enterprises. What is meant here is a perception of the relative severity of the tax problem, compared to other problems. 


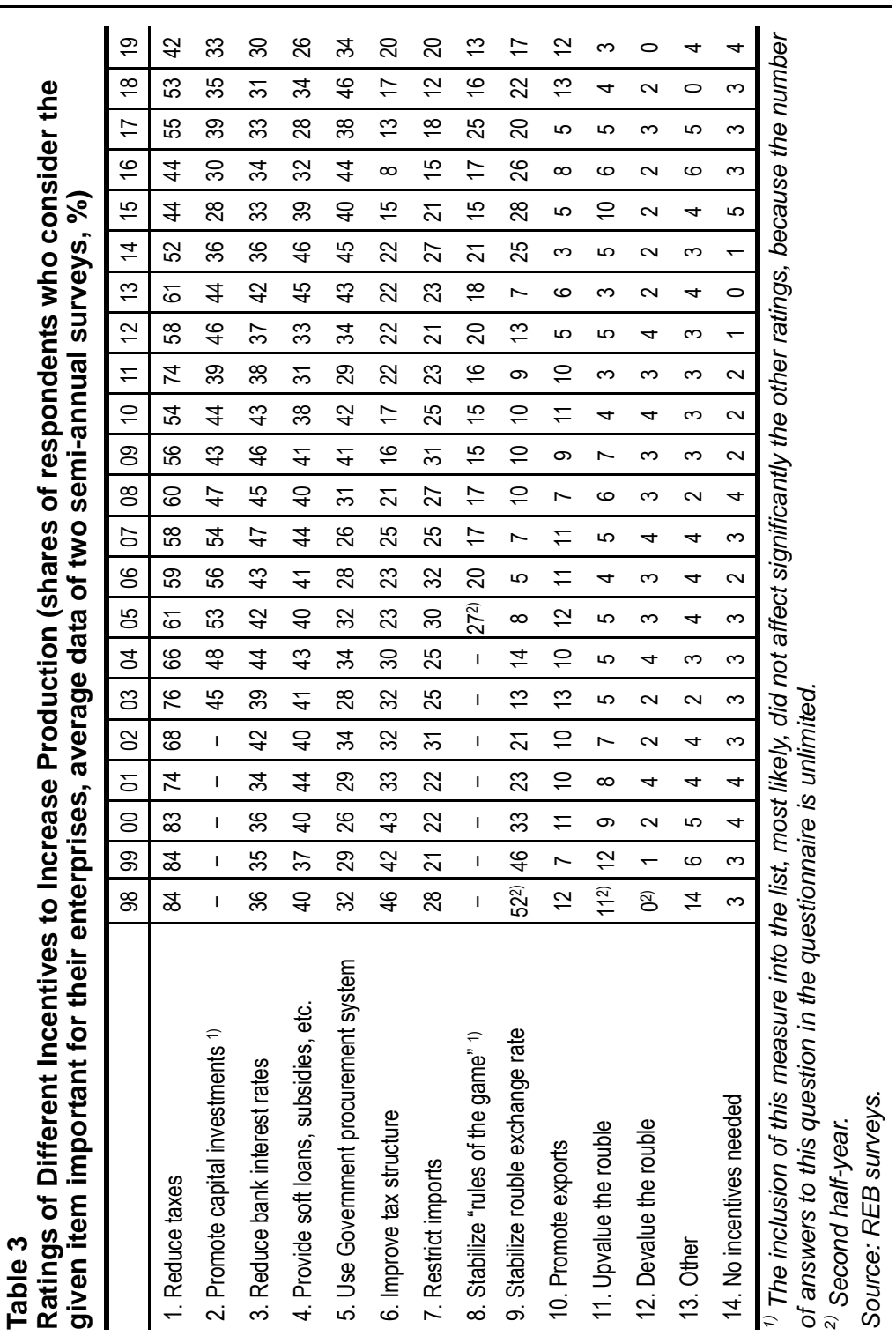


"Use of the Government procurement system" abruptly came to the second position with $46 \%$ in 2018 and retained it in 2019, declining however to $34 \%$. This is just 1 percentage point more than the thirdplace measure of "providing capital investment incentives" (33\%). The fourth and fifth lines in the rating were taken by measures to reduce the cost of bank credit (30\%) and to provide preferential loans, grants, etc. to enterprises $(26 \%)$. And in the latter case, we have a record low value of the indicator for the entire history of its measurement (since 1998).

Among the measures of lesser importance, our attention should be drawn to some increase in popularity of the ideas of import restrictions (from $12 \%$ in 2018 to $20 \%$ in 2019 ) and of tax structure's improvement (from $17 \%$ in 2018 to $20 \%$ in 2019). On the contrary, there was a significant decline in the shares of respondents supporting measures to stabilize the "rules of the game" (from 16\% in 2018 to 13\% in 2019) and the ruble exchange rate (from 22 to 17\%). Apparently, the severity of these two problems for the enterprises has actually decreased recently.

Apart from assessing specific measures of economic policy from the enterprises' point of view, the REB's respondents were asked about the relative importance of stimulating production versus lowering inflation for the Russian economy on the whole. As can be seen from table 4, throughout the period under assessment, the numerical superiority of production increase supporters over inflation decline supporters was overwhelming. It remained the same in 2019: $72 \%$ of respondents believed that production was more important than inflation, and only $13 \%$ were of the opposite opinion. 
Table 4

Distribution of Answers to the Question "What is More Important for Russian Economy at Present: to Lower the Inflation Rate or to Promote the Production?" (Shares of respondents who chose a given version, average data of four quarterly surveys, \%)

\begin{tabular}{c|c|c|c|c}
\hline & Inflation & Both equally & Production & Balance \\
\cline { 2 - 5 } & $(1)$ & $(2)$ & $(3)$ & $(4)=(3)-(1)$ \\
\hline 1997 & 2 & 4 & 94 & 92 \\
1998 & 2 & 3 & 95 & 93 \\
1999 & 5 & 6 & 89 & 84 \\
2000 & 5 & 5 & 90 & 85 \\
2001 & 6 & 6 & 88 & 82 \\
2002 & 7 & 7 & 86 & 79 \\
2003 & 7 & 7 & 86 & 79 \\
2004 & 6 & 7 & 87 & 81 \\
2005 & 7 & 4 & 89 & 82 \\
2006 & 9 & 6 & 85 & 76 \\
2007 & 9 & 7 & 84 & 75 \\
2008 & 17 & 9 & 74 & 57 \\
2009 & 9 & 9 & 82 & 73 \\
2010 & 11 & 12 & 77 & 66 \\
2011 & 14 & 12 & 74 & 60 \\
2012 & 11 & 12 & 77 & 66 \\
2013 & 13 & 15 & 72 & 59 \\
2014 & 13 & 17 & 70 & 57 \\
2015 & 12 & 18 & 70 & 58 \\
2016 & 11 & 16 & 73 & 62 \\
2017 & 9 & 13 & 78 & 69 \\
2018 & 11 & 18 & 71 & 60 \\
2019 & 13 & 15 & 72 & 59 \\
\hline $50 u r e: R E B$ & & & & \\
\hline
\end{tabular}

Source: REB surveys. 
Over the past 10 years there has been an increase in the relative importance of anti-inflationary policy in the eyes of respondents. The importance of this policy received its record high assessments in 20082015 (excluding 2009), when high inflation sharply contrasted with the slowdown in production. According to our data, this contrast was eliminated in 2016: production seemingly went upwards, and inflation, on the contrary, radically declined. Apparently, this was the reason for the breakdown of the above-mentioned tendency. The data for 2017 also fit well into this logic: inflation almost disappeared, whereas production grew hard and slowly. That is why the emphasis on stimulating production became stronger. As for 2018, we should pay attention to the record high value of the third answer, offering "equally" to counteract inflation and to stimulate production. Apparently, the fear of resuming a rapid price increase (with certain grounds for it) was combined with the expectation of a new recession (equally reasonable). In our opinion, the same logic can be seen in the respondents' answers in 2019.

In general, despite all the fluctuations, the structure of respondents' assessments is very far from that observed in the late 1990s and in the zero years of the new century. It seems that the majority of those who underestimated the importance of anti-inflationary policy $10-15$ years ago have now changed their minds.

\section{Agricultural Enterprises}

The comprehension of the Government's economic policy among the respondents of agricultural enterprises of the REB sample increased by 1 percentage point - to 49. By historical standards, this is a record high value. In other words, as a year ago, almost half of respondents believed that they understood the sense of government's economic actions.

The economic policy approval indicator increased by 2 percentage points - to 40 . This is only 1 point less than the record high value for 2015. 
Table 5

Assessments of the Government's Economic Policy (conducted in the last three to four months) and of the Residual Duration of Crisis by Agricultural Managers (average data of four quarterly surveys)

\begin{tabular}{|c|c|c|c|c|}
\hline & $\begin{array}{c}\text { Index of comprehension } \\
\text { of Government's } \\
\text { economic policy } 1 \text { ) }\end{array}$ & $\begin{array}{l}\text { Index of approval } \\
\text { of Government's } \\
\text { economic policy') }\end{array}$ & \multicolumn{2}{|c|}{$\begin{array}{l}\text { Residual duration of crisis, years }{ }^{2} \\
\text { (in brackets - excess over the assessments } \\
\text { for the industry from Table 1) }\end{array}$} \\
\hline 19923) & & & 6.2 & $(+0.2)$ \\
\hline 1993 & 39 & 29 & 6.8 & $(+0.8)$ \\
\hline 1994 & 32 & 22 & 7.8 & $(+1.5)$ \\
\hline 1995 & 29 & 19 & 8.3 & $(+1.2)$ \\
\hline 1996 & 30 & 18 & 7.8 & $(+1.1)$ \\
\hline 1997 & 34 & 19 & 9.0 & $(+1.2)$ \\
\hline 1998 & 37 & 21 & 9.2 & $(+1.8)$ \\
\hline 1999 & 39 & 32 & 7.6 & $(-0.1)$ \\
\hline 2000 & 41 & 31 & 7.5 & $(+1.5)$ \\
\hline 2001 & 44 & 34 & 7.1 & $(+0.7)$ \\
\hline 2002 & 41 & 32 & 8.8 & $(+1.7)$ \\
\hline 2003 & 41 & 25 & 9.8 & $(+2.3)$ \\
\hline 2004 & 45 & 27 & 10.6 & $(+3.0)$ \\
\hline 2005 & 37 & 23 & 11.6 & $(+3.8)$ \\
\hline 2006 & 47 & 31 & 10.5 & $(+3.4)$ \\
\hline 2007 & 44 & 34 & 9.0 & $(+2.2)$ \\
\hline 2008 & 44 & 37 & 8.7 & $(+2.8)$ \\
\hline 2009 & 38 & 36 & 7.7 & $(+3.5)$ \\
\hline 2010 & 38 & 34 & 8.1 & $(+3.7)$ \\
\hline 2011 & 37 & 31 & 9.6 & $(+4.7)$ \\
\hline 2012 & 42 & 36 & 7.6 & $(+1.9)$ \\
\hline 2013 & 40 & 32 & 9.2 & $(+3.5)$ \\
\hline 2014 & 34 & 26 & 9.0 & $(+3.1)$ \\
\hline 2015 & 44 & 41 & 7.4 & $(+2.4)$ \\
\hline 2016 & 45 & 40 & 7.7 & $(+1.7)$ \\
\hline 2017 & 38 & 34 & 11.3 & $(+4.8)$ \\
\hline 2018 & 48 & 38 & 9.7 & $(+2.4)$ \\
\hline 2019 & 49 & 40 & 7.4 & $(+0.9)$ \\
\hline
\end{tabular}

The data for 2012-2014 were adjusted.

1) A 100-point scale: "100" corresponds to the case when all managers comprehend/approve of the policy, while "0" to the case when none of them comprehend/approve of it.

${ }^{2}$ In the cases when the respondents believed that the crisis was already over, assessment of residual duration of the crisis was taken as zero.

${ }^{3)}$ Without the first quarter.

Source: REB surveys. 
The assessment of the residual duration of the crisis decreased by more than two years - to 7.4 years. This is almost a record low estimate for the last 26 years. The respondents' expectations were even more optimistic only in 1992-1993 (6.2-6.8 years) and in 2001 (7.1). As for the discrepancy between the estimates of the residual duration of the crisis by the agricultural and industrial managers, it dropped two and a half times: from +2.4 to +0.9 years. These two estimates of the residual duration of the crisis were not so close to each other during 18 years.

On the whole, the results of our measurements allow us to make a conclusion that the industrial managers' support for the Government's economic policy almost didn't change in 2019 compared with the previous year, remaining at a high level by historical standards. At the same time, it slightly increased among the agricultural managers. 